\title{
Rendimento em madeira serrada de Cupressus Iusitanica Mill por meio do sistema de desdobro tangencial
}

\author{
Sawn wood yield of Cupressus Iusitanica Mill \\ by the tangential sawing system
}

\begin{abstract}
Alexsandro Bayestorff Cunha ${ }^{1}$, Martha Andreia Brand ${ }^{1}$, Caio Cesar Faedo de Almeida ${ }^{2}$, Camile Sothe ${ }^{2}$, Larissa Pasa Martarello² e Luciane Gorski ${ }^{2}$
\end{abstract}

\begin{abstract}
Resumo
O objetivo do estudo foi avaliar o rendimento da matéria-prima de Cupressus lusitanica Mill por meio do processo de desdobro tangencial para duas classes diamétricas, de 20 a $27 \mathrm{~cm}$ (I) e acima de $27,1 \mathrm{~cm}$ (II). A avaliação do rendimento do processo de desdobro foi realizada por meio da determinação dos rendimentos: bruto; com destopo das seções com nós; com destopo e refilo das seções com esmoado; e com destopo e refilo das seções rachadas e rendimento líquido do processo. Ao mesmo tempo, foram quantificados os defeitos naturais e decorrentes do processo. Os resultados demonstraram que o Cupressus lusitanica apresentou bom desempenho no processo de desdobro tangencial quando comparado a outras espécies de coníferas, sendo a média do rendimento líquido de $43,65 \%$ para a classe I e $45,24 \%$ para a classe II. Em geral, a classe diamétrica superior apresentou menos defeitos que ocasionaram em menor perda de rendimento em relação à classe I. As flechas de arqueamento, mesmo que pouco expressivas, foram mais evidentes para a menor classe diamétrica. Em relação à presença de nós e rachaduras, a classe I apresentou maior número de peças com os defeitos, e tamanho mais expressivo de nós e rachaduras ao longo das peças que a classe II.
\end{abstract}

Palavras-chave: Cipreste, madeira serrada, defeitos da madeira.

\begin{abstract}
The aim of the study was to evaluate the yield of raw Cupressus /usitanica Mill wood by the tangential sawing process for two diameter classes, from 20 to $27 \mathrm{~cm}$ (I) and greater than $27.1 \mathrm{~cm}$ (II). The performance evaluation of the sawing process was performed by the determination of yield: gross, with cross-sectional sections with knots, with transverse cutting and trimming of the sections with ground edge,and cross-cutting and trimming of cracked sections and net yield of the process. At the same time, natural and processing defects were quantified. The results showed that Cupressus lusitanica performed well in the tangential sawing process when compared to other species of conifers, and the average net yield was $43.65 \%$ for grade I and $45.24 \%$ for class II. Overall, the higher diameter class had fewer defects that resulted in lower yield loss than in class I. The arrow archings, even though of little significance, were more evident for the smallest size class. As for the presence of knots and cracks, class I had the greatest number of pieces with defects, size and most expressive knots and cracks along parts of the class II.
\end{abstract}

Keywords: Cypress, lumber, wood defects.

\section{INTRODUÇÃO}

Ao longo das últimas décadas, o perfil de consumo de madeiras mudou consideravelmente em função das restrições de exploração e da disponibilidade de espécies florestais nativas. Diante disso, a madeira de florestas plantadas veio a ocupar esta lacuna, disponibilizando rápida aquisição de matéria-prima para os mais diversos segmentos (SANTOS; AGUIAR, 2007).

Além das espécies amplamente difundidas em reflorestamentos por todo o país como o Pinus taeda, o Pinus elliottii e o Eucalyptus grandis, outras espécies de rápido crescimento devem ser consideradas para atender a demanda crescente de matéria-prima, de modo a contribuir de forma quantitativa e qualitativa para suprir as necessidades das indústrias, bem como, contribuir para o desenvolvimento e geração de novos produtos (TRIANOSKI, 2010)

${ }^{1}$ Professor Doutor do Departamento de Engenharia Florestal. UDESC - Universidade do Estado de Santa Catarina. Av. Luis de Camões, 2090, Lages, SC - 88520-000. E-mail: alexsandro.cunha@udesc.br; martha.brand@udesc.br

${ }^{2}$ Mestre em Engenharia Florestal. UDESC - Universidade do Estado de Santa Catarina. Av. Luis de Camões, 2090, Lages, SC - 88520-000. E-mail: caio-almeida@florestal.eng.br; camilesothe@yahoo.com.br; laripasa@msn.com; lu_gorski@hotmail.com; 
Dentre as espécies não convencionais, várias vem sendo estudadas e estão apresentando potencial para os mais diferentes produtos como Toona ciliata, Melia azedarach e Schizolobium parahyba (TRIANOSKI, 2010), Schizolobium amazonicum (NAUMANN et al., 2008), Cecropia hololeuca (IWAKIRI et al, 2012a), Pinus maximinoi (KLOCK, 2000), P. oocarpa e P. tecunumannii (IWAKIRI et al, 2009), Cryptomeria japônica (PINTO, 2011) e Sequoia sempervirens (IWAKIRI et al, 2012b; IWAKIRI et al, 2012a).

Segundo Alves et al. (2011), na região Sul do Brasil as condições climáticas representam o principal entrave ao aumento das áreas de plantio de espécies de rápido crescimento, sendo que estudos de espécies resistentes ao frio são de grande importância para o setor de base florestal nestes estados.

Dentre as espécies de coníferas não convencionais com potencial de cultivo na região Sul do Brasil, destacam-se os ciprestes como o Cupressus lusitanica Mill, que está presente em plantios experimentais nos Estados de Santa Catarina e Paraná (OKINO et al., 2008).

Conhecida no Brasil principalmente pela utilização ornamental, como cerca-viva e quebra-ventos, o C. lusitanica pode ser manejado para a produção de madeira, inclusive em pequenas propriedades rurais, visto que tolera vários tipos de solo (SHIMIZU et al., 2006).

A madeira de C. lusitanica apresenta características como odor agradável e característico da espécie, densidade variando de 0,40 a $0,57 \mathrm{~g} / \mathrm{cm}^{3} \mathrm{com}$ pequena distinção entre alburno e cerne, coloração amarelada, grã reta e textura fina e uniforme e bastante promissora para a implantação de florestas homogêneas. (PEREIRA et al., 2003; OKINO et al., 2006; OKINO et al., 2010).

Em relação ao desdobro do C. lusitanica em serraria, tem-se poucas informações para a promoção do uso tecnológico adequado da espécie, fazendo necessário determinar o rendimento em madeira serrada no processo e consequentemente a sua qualidade por meio da seleção das toras por classe diamétrica, otimização do sistema de desdobro através de softwares, visores óticos para detecção de defeitos durante o desdobro, layout adequados aos sistemas de beneficiamentos, entre outros. (NÉRI et al., 2005).

O objetivo do estudo foi avaliar o rendimento em madeira serrada do Cupressus lusitanica Mill. por meio do processo de desdobro tangencial aplicado a duas classes diamétricas. Ao mesmo tempo, foram quantificados os defeitos naturais e decorrentes do processo, determinando as suas influências no rendimento líquido do desdobro.

\section{MATERIAL E MÉTODOS}

\section{Matéria-prima}

A madeira de utilizada no estudo foi proveniente de um plantio experimental com 19 anos de idade, localizado em Campo Belo do Sul, Santa Catarina. No experimento foram utilizadas 42 toras com comprimento de $2 \mathrm{~m}$ e diâmetro variando entre 20 e $40 \mathrm{~cm}$, as quais foram obtidas a partir de oito árvores com características médias de 33,6 cm de DAP $(28,3$ a 39,5 cm), 19,7 m de altura total $(18,7$ a $19,9 \mathrm{~m})$ e $15,2 \mathrm{~m}$ de altura comercial $(14,9$ a $17,2 \mathrm{~m})$.

Para a separação das toras em duas classes diamétricas, procedeu-se a medição do diâmetro em três posições (ponta fina, porção mediana e ponta grossa). De posse do diâmetro médio de todas as toras disponíveis, definiu-se as classes diamétricas, 20 a $27 \mathrm{~cm}$ e acima de $27,1 \mathrm{~cm}$, sendo a primeira denominada de Classe I e a segunda de Classe II.

\section{Delineamento experimental}

Foram utilizados dois tratamentos, os quais foram caracterizados de acordo com a classe diamétrica, sendo que cada um dos tratamentos foi composto por 21 toras distribuídas em três amostras de sete toras cada um. A avaliação do rendimento do processo de desdobro foi realizada por meio do: (1) rendimento bruto, (2) rendimento com destopo das seções com nós, (3) rendimento com destopo e refilo das seções com esmoado e com nós, (4) rendimento com destopo e refilo das seções rachadas e (5) rendimento líquido do processo. Outras avaliações desenvolvidas no experimento foram a determinação das flechas de arqueamento e a mensuração dos nós, rachaduras e esmoado.

\section{Rendimento do processo de desdobro}

Foi obtido pela relação entre o volume de madeira serrada gerado no processo de desdobro de cada repetição e o somatório do volume das toras. Para a determinação do volume das toras, utilizou-se o método de Smalian. Na determinação do volume de madeira serrada, mediu-se a es- 
pessura e a largura em três pontos da peça (porção mediana e a $50 \mathrm{~mm}$ de cada extremidade) e o comprimento na parte central. Mensurou-se também as rachaduras existentes nas quatro faces da peça e os locais onde havia necessidade de fazer um destopo e refilo pela presença de esmoado ou nós, obtendo-se desta forma, os cinco rendimentos supracitados.

O sistema de desdobro aplicado envolveu a passagem das toras em um serra fita horizontal onde era feito um corte por baixo, ou seja, retirada de uma costaneira na parte de baixo da tora. A porção maior da tora foi reprocessada em uma serra fita dupla, sendo retirado um semi-bloco e mais duas costaneiras. O semi-bloco foi direcionado a uma sequência de quatro serras de fita horizontais para obtenção das peças de madeira serrada. Já as três costaneiras foram refiladas em uma serra circular múltipla e resserradas em uma sequência de duas serras de fita horizontais, conforme apresentado na figura 1.
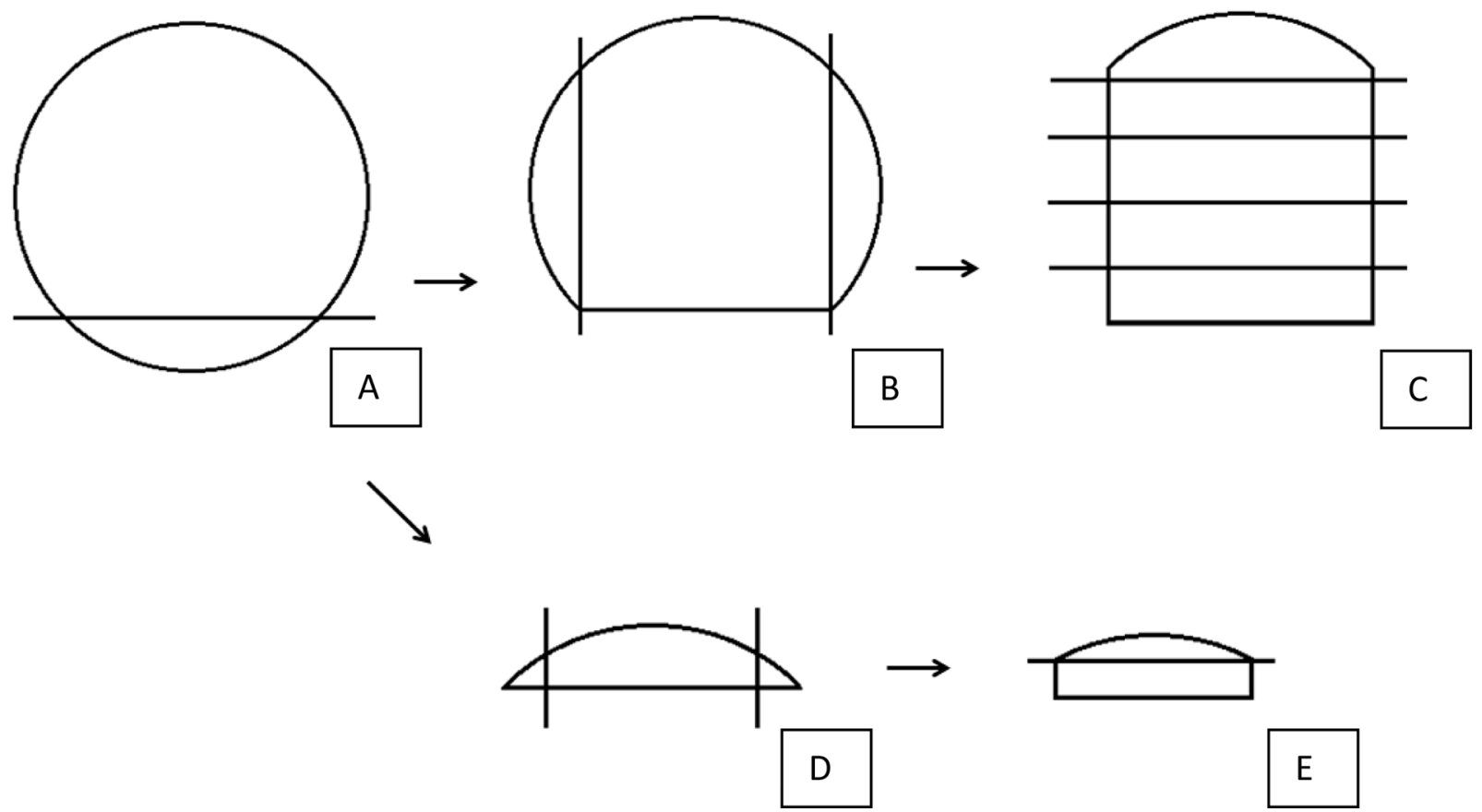

Figura 1. Modelo de corte tangencial utilizado no desdobro das toras. (A) serra fita horizontal; (B) serra fita dupla; (C) serra fita horizontal de quatro cabeçotes; (D) serra circular múltipla; (E) serra fita horizontal.

Figure 1. Tangential cutting pattern used in sawing the logs. (A) Horizontal band saw; (B) Twin band saw; (C) Four head horizontal band saw; (D) Multiple circular saw; (E) Horizontal band saw.

As dimensões das peças obtidas no processo de desdobro foram 1,90 m de comprimento, 140 $\mathrm{mm}$ de largura e $15 \mathrm{~mm}$ de espessura, as quais originam peças para a produção de cercas que são exportadas para os Estados Unidos.

A classificação das peças de madeira serrada seguiu o padrão de comercialização adotado pela empresa responsável pelo desdobro (Boa Esperança Indústria Comércio e Exportação de Madeira, Capão Alto - SC), onde a madeira era selecionada de acordo com a qualidade das peças, sendo:

- Peças "A": peças totalmente livres de defeitos;

- Peças "B": peças com poucos defeitos e com pequena intensidade, como a presença de nós firmes e medula. No entanto, não aceita que a peça apresente defeitos que necessitem de destopos e refilo, como no caso de rachaduras de topo, nós de canto e esmoados.

As peças não classificadas como " $\mathrm{A}$ " ou " $\mathrm{B}$ " foram remarcadas para refilo e destopo, ou seja, para a linha de reaproveitamento, onde foram classificadas de acordo com o tipo e intensidade dos defeitos. Neste reaproveitamento, as peças deveriam apresentar comprimento mínimo de $200 \mathrm{~mm}$ e larguras padronizadas de 110, 80 e $60 \mathrm{~mm}$. As peças reaproveitadas tinham como destino as indústrias moveleiras do Planalto Sul Catarinense.

\section{Quantificação dos defeitos naturais e de processo}

A quantificação dos defeitos ao longo das peças foi baseada nos procedimentos da NBR 12297 (ABNT, 1991) e da NBR 1030 (ABNT, 2010), que tratam da medição e quantificação de defeitos em madeiras serradas de coníferas. 
A atividade foi dividida em quatro etapas, sendo que a primeira consistiu na medição dos empenamentos, sendo determinado somente a flecha de arqueamento em virtude da pouca expressão dos outros defeitos como encurvamento, encanoamento e torcimento.

Na segunda etapa foi efetuada a medição dos nós, onde se considerou apenas os nós na face e na quina das peças. Os defeitos foram medidos no sentido do comprimento da peça na face mais representativa (com maior número de nós). Ao final, o comprimento de todos os nós foi somado, sendo possível determinar a porcentagem de nós em relação ao comprimento de cada tábua.

A terceira etapa realizada foi a determinação do comprimento das rachaduras ao longo das peças, sendo que este defeito foi observado sempre na pior face da tábua, além de terem sido avaliadas apenas as peças verdes, isto é, não abrangeu processos de secagem. As rachaduras foram classificadas em pequena (até $5 \mathrm{~cm}$ ), média $(5,1 \mathrm{a} 20 \mathrm{~cm}$ ) ou grande (acima de $20 \mathrm{~cm})$, conforme a medição ao longo da peça. E por fim, a última etapa das medições quantificou a presença de esmoado nas tábuas, isto é, quinas mortas ou ausência de madeira ao longo do comprimento das peças. Ambos os procedimentos foram realizados com fitas métricas, devido à extensão dos defeitos nas peças.

\section{Análise dos dados}

$\mathrm{Na}$ análise do rendimento, os dados foram testados quanto à presença de outliers (análise gráfica (boxplot)), normalidade da distribuição (Kolmogorov-Smirnov) e homogeneidade de variâncias (Teste de Levene). Posteriormente, os dados foram avaliados por meio da Análise da Variância, e em caso de diferença estatística foi aplicado o Teste de Scott Knott a 95\% de probabilidade.

Nos resultados relativos aos defeitos naturais e de processo das peças, fez-se a determinação do número e porcentagem das peças em que os defeitos estavam presentes, além das medidas de tendência central e de dispersão: média, valor mínimo e valor máximo.

\section{RESULTADOS E DISCUSSÃO}

\section{Rendimento do processo de desdobro}

Os valores obtidos para os rendimentos em madeira serrada do desdobro das toras de C. lusitânica estão apresentados na tabela 1, onde observa-se diferenças estatísticas entre o rendimento bruto e líquido do processo para as duas classes diamétricas. Ao mesmo tempo, nota-se que nesta análise o rendimento bruto não diferenciou estatisticamente dos rendimentos isolados (sem esmoado, sem nós e sem rachaduras).

Tabela 1. Rendimento do processo de desdobro.

Table 1. Sawing process yield.

\begin{tabular}{lcccccc}
\hline \multirow{2}{*}{ Rendimento } & \multicolumn{3}{c}{ Classe I } & \multicolumn{3}{c}{ Classe II } \\
\cline { 2 - 7 } & $\mathbf{V T}\left(\mathbf{m}^{\mathbf{3}}\right)$ & $\left.\mathbf{V M S} \mathbf{( m}^{\mathbf{3}}\right)$ & $\mathbf{R}(\mathbf{\%})$ & $\left.\mathbf{V T} \mathbf{( m}^{\mathbf{3}}\right)$ & $\mathbf{V M S}\left(\mathbf{m}^{3}\right)$ & $\mathbf{R} \mathbf{( \% )}$ \\
\hline Bruto & 1,7521 & 1,0944 & $62,46 \mathrm{Aa}$ & 3,0962 & 1,8181 & $58,72 \mathrm{Aa}$ \\
Sem esmoado & 1,7521 & 0,9794 & $55,90 \mathrm{Aa}$ & 3,0962 & 1,6577 & $53,54 \mathrm{Aa}$ \\
Sem nós & 1,7521 & 0,9968 & $56,89 \mathrm{Aa}$ & 3,0962 & 1,6905 & $54,60 \mathrm{Aa}$ \\
Sem rachadura & 1,7521 & 0,9759 & $55,70 \mathrm{Aa}$ & 3,0962 & 1,6856 & $54,44 \mathrm{Aa}$ \\
Líquido & 1,7521 & 0,7648 & $43,65 \mathrm{Ba}$ & 3,0962 & 1,4007 & $45,24 \mathrm{Ba}$ \\
\hline
\end{tabular}

Legenda: VT: volume de toras; VMS: volume de madeira serrada; R: rendimento do processo de desdobro. Bruto: total serrado com todos os defeitos. Sem esmoado: serrado com a retirada de esmoado por meio de refilo. Sem nós: serrado com a retirada dos nós por meio de destopo. Sem rachaduras: serrado sem as partes rachadas das peças, as quais foram retiradas por meio de refilo e/ou destopo. Líquido: total serrado sem os defeitos naturais e de processo (esmoado, nós e rachaduras). Médias seguidas de mesma letra maiúscula na coluna e de mesma letra minúscula na linha não diferenciam estatisticamente entre si a de $95 \%$ de probabilidade pelo teste de Scott Knott.

O rendimento bruto da classe I $(62,46 \%)$, de menor diâmetro, foi superior numericamente ao da classe II $(58,72 \%)$, o que não é característico, tendo em vista que quanto maior o diâmetro das toras (TSOUMIS, 1991), maior é o rendimento. Este fato pode ser atribuído ao modelo de corte não específico para a classe e nem para os produtos obtidos a partir dela, ou seja, a classe diamétrica superior pode não ter se adaptado ao modelo de corte utilizado, tendo como consequência uma grande geração de resíduos, proporcionado pelo maior número de cortes do que o realizado na classe diamétrica inferior. 
A redução do rendimento bruto para o líquido do processo de desdobro foi de $18,81 \%$ para a classe I e de 13,48\% para as toras da classe II. As causas das maiores perdas serem encontradas na classe inferior são devido a maior conicidade das toras de menor diâmetro o que reflete em maior quantidade de esmoado e também em função de não haver poda na área experimental, ou seja, somente desrama natural o que acaba tendo como consequência a maior ocorrência de nós nas porções superiores das árvores.

Egas (2000) corrobora com a afirmação, citando que o rendimento diminui com a redução da qualidade das toras, uma vez que é perdida muita madeira ao se eliminar defeitos no desdobro de toras de baixa qualidade. Vianna Neto (1984) menciona também que a qualidade da matéria-prima pode influenciar em até $70 \%$ no êxito da obtenção de um ótimo rendimento.

Rocha (2002); Vital (2008) citam que um rendimento satisfatório para coníferas deve estar no entre 55 e 65\%, assim verifica-se que somente o rendimento bruto do processo se enquadrou no intervalo proposto pelos autores. Porém, todos os rendimentos ficaram dentro do intervalo encontrado por Cardoso Jr. (2008) para madeira serrada de Pinus spp (32,6 a 61,7\%), a qual é utilizada tradicionalmente na região sul.

Para fins comparativos entre coníferas, Biasi e Rocha (2003), desdobrando toras de Pinus elliottii com diâmetro entre $8 \mathrm{~cm}$ e $45 \mathrm{~cm}$ e utilizando diagramas de corte específicos para as classes estudadas, obtiveram um rendimento médio $43,17 \%$, o que foi inferior à média de $53,60 \%$ obtida na pesquisa de Murara Jr. (2005), trabalhando com Pinus taeda com diâmetro entre 18 e $44 \mathrm{~cm}$.

Outros estudos com Pinus spp e com classes diamétricas semelhantes ao do presente trabalho demonstraram rendimentos brutos inferiores, como relatado por Pinto et al. (2006) que observaram rendimento de 57\%, Olandoski et al. (1998) com 50\%, Manhiça (2010) com 52\%, Fontes (1994) com 30,5\% e Cademartori (2010) que obteve rendimento mínimo de 38,60\% e máximo de 53,77\%.

Em relação à diferença de rendimento entre as duas classes diamétricas analisadas, Rocha (2000) menciona que é normal em serrarias, onde as toras de menores diâmetros apresentarem menores rendimentos. No entanto, no presente estudo a classe de menor diâmetro foi a que apresentou numericamente maior rendimento bruto, fato que pode ser explicado em função do diâmetro de tora mais elevado não ser adequado para o produto gerado no desdobro ou ainda pelo modelo de corte não ser específico para cada uma das classes diamétricas.

Da mesma forma, o comportamento de menor rendimento volumétrico bruto de madeira serrada para a classe diamétrica superior, pode ser relacionado ao desempenho serrarias que processam toras de coníferas de pequenos diâmetros, citado por Ponce (1984), na qual o rendimento do desdobro cresce rapidamente quando se considera toras a partir de $15 \mathrm{~cm}$ até $30 \mathrm{~cm}$ de diâmetro. Entretanto, a partir de $30 \mathrm{~cm}$ registra-se um crescimento menos acentuado.

Para Murara Jr. (2005), o comportamento do desdobro de toras de Pinus sp. demonstra uma relação próxima entre o aumento do diâmetro com o aumento dos rendimentos médios do desdobro. Podendo-se destacar a tendência de aumento do rendimento líquido, sem defeitos, em aproximadamente $2 \%$ à medida que se aumenta o diâmetro das toras, isto é, da classe I para a classe II, embora o maior rendimento bruto possa ser observado para a classe de diâmetros menores, corroborando o que diz respeito ao maior número de defeitos na madeira serrada encontrado para a classe I.

Não havendo diferença estatística significativa comparando as duas classes diamétricas selecionadas para o estudo, tem-se que, além das informações acerca da qualidade e rendimento do desdobro da madeira de Cupressus lusitanica, o conhecimento sobre a cultura permite o manejo adequado quanto ao ciclo da espécie e fornece uma importante ferramenta para o produtor rural definir o uso final de seu povoamento.

\section{Flechas de arqueamento}

A quantificação das flechas de arqueamento está apresentada na Tabela 2, onde se pode observar que as peças da classe I apresentaram os maiores valores, os quais variaram de 1,4 a 10,8\% da largura das peças. Ao mesmo tempo, a classe diamétrica inferior apresentou maior número de peças sem arqueamento, 85,5\% contra 70,5\% da classe superior. Ainda, a classe superior não apresentou nenhuma peça com o defeito classificado como grande, ou seja, empenamento com flecha superior a $10 \%$. 
Cunha et al. - Rendimento em madeira serrada de Cupressus

lusitanica Mill por meio do sistema de desdobro tangencial

Tabela 2. Intensidade de ocorrência de flechas de arqueamento nas peças.

Table 2. Intensity of occurrence of bowing arrows in the wooden pieces.

\begin{tabular}{lcccc|cccc}
\hline & \multicolumn{4}{c}{ Classe I } & \multicolumn{5}{c}{ Classe II } \\
\hline Defeito & NA & $\mathbf{1}$ & $\mathbf{2}$ & $\mathbf{3}$ & NA & $\mathbf{1}$ & $\mathbf{2}$ & $\mathbf{3}$ \\
\hline $\mathrm{N}^{\circ}$ de peças & 236 & 14 & 25 & 1 & 288 & 41 & 95 & -- \\
\% de peças & 85,5 & 5,1 & 9,1 & 0,4 & 70,5 & 9,7 & 22,4 & -- \\
Mínima & -- & 1,4 & 2,6 & 10,8 & -- & 0,9 & 3,6 & -- \\
Máxima & -- & 2,5 & 7,9 & 10,8 & -- & 2,5 & 8,0 & -- \\
Média & -- & 2,0 & 3,5 & 10,8 & -- & 2,1 & 3,5 & -- \\
\hline
\end{tabular}

NA - Não Apresentou I - Pequeno: Empenamento com flecha de até 2,5\% da largura da tábua; 2 - Médio: Empenamentos com flecha de 2,5 a 10\%; 3 - Grande: Empenamentos com flecha superior a 10\%.

Cabe salientar que a ausência das flechas de encurvamento, encanoamento e torcimento, além das flechas de arqueamento poucos expressivas se deve a baixa massa específica básica da espécie, $0,31 \mathrm{~g} / \mathrm{cm}^{3}$ e também ao baixo coeficiente anisotrópico, 1,54, os quais foram determinados por Almeida (2015). No entanto, é interessante verificar as variáveis supracitadas após a operação de secagem artificial, onde o programa de secagem aplicado e as características da estufa poderão influenciar diretamente na qualidade das peças de madeira serrada.

\section{Quantificação dos nós ao longo da peça}

Os dados relativos à quantidade e comprimento de nós para as duas classes diamétricas estão apresentados na tabela 3, onde pode-se observar que na classe I, 93\% das peças serradas apresentaram o defeito, já na classe II a proporção foi de 70\%. Além disto, o tamanho e a quantidade de nós foi maior na classe I onde o valor médio foi de $357,8\left(\mathrm{~mm} / \mathrm{m}^{2}\right)$, já para a classe superior o comprimento médio dos nós foi de 131,9 $\left(\mathrm{mm} / \mathrm{m}^{2}\right)$. Como já mencionado anteriormente, em virtude do caráter experimental do povoamento, não foram realizados alguns tratos culturais como a desrama. No entanto, o adensamento das árvores promove a ocorrência de desrama natural, que resultam em nós de pequenas dimensões não comprometendo gravemente a qualidade.

Tabela 3. Percentual de nós nas peças de madeira serrada de C. lusitanica.

Table 3. Knot Percentage in C. lusitanica wood.

\begin{tabular}{|c|c|c|c|c|}
\hline Defeito & & & \multicolumn{2}{|c|}{ Classe II } \\
\hline $\mathrm{N}^{\circ}$ de peças com nós & & & \multicolumn{2}{|c|}{295} \\
\hline$\%$ de peças & & & \multicolumn{2}{|c|}{69,6} \\
\hline Mínimo (mm) & & & \multicolumn{2}{|c|}{10,96} \\
\hline Máximo (mm) & \multicolumn{2}{|c|}{651,94} & \multicolumn{2}{|c|}{506,96} \\
\hline Média & $357,8\left(\mathrm{~mm} / \mathrm{m}^{2}\right)$ & $49,4(\% / m)$ & $131,9\left(\mathrm{~mm} / \mathrm{m}^{2}\right)$ & $28,3(\% / \mathrm{m})$ \\
\hline
\end{tabular}

Segundo Gatto et al. (2004), a nodosidade é um fator que limita o uso da madeira influenciando no rendimento e na qualidade do produto final madeireiro. Em seu estudo com Pinus sp., a média do diâmetro dos nós foi de $33,4 \mathrm{~mm}$ e a proporção de nós igual a $35 \% / \mathrm{m}$. Além de terem obtido apenas $58,4 \%$ de nós firmes, o resto classificou-se como nó solto $(22,1 \%)$, cariado $(14,8 \%)$ ou gravata $(4,7 \%)$, em contrapartida destaca-se que no estudo em questão, com C. lusitanica, todos os nós observados foram firmes e com aparência clara.

No estudo de Cademartori (2012), com Pinus elliottii, as peças oriundas da tora superior apresentaram valores de proporção de nós significativamente superiores quando comparados com as peças oriundas da tora basal, pelo fato de a floresta responsável por abastecer a serraria não sofrer nenhum tipo de manejo silvicultural, especificamente a desrama. Ainda, diz que a quantidade de nós aumenta significativamente com a altura do tronco na direção da copa da árvore.

Shimizu et al. (2006) afirma que para a produção de madeira para serraria, o Cupressus lusitanica Mill. deve, desde cedo (cerca de 2 anos), sofrer desrama artificial quando em plantios puros já que a madeira é muito nodosa. $\mathrm{O}$ autor recomenda que a desrama deve ser realizada a cada três anos, iniciando-se aos cinco anos de idade. 


\section{Rachaduras}

A presença de rachaduras nas peças de madeira desdobradas foi maior na classe diamétrica I, sendo que $37,5 \%$ das peças avaliadas no estudo apresentaram algum tipo de rachadura, contra apenas $2,4 \%$ das peças da classe II (Tabela 4 ).

Tabela 4. Porcentagem de rachaduras nas peças de madeira serrada.

Table 4. Percentage of cracks in the lumber.

\begin{tabular}{lcccc|cccc}
\hline & \multicolumn{4}{c}{ Classe I } & \multicolumn{4}{c}{ Classe II } \\
\hline Rachaduras & NA & $\mathbf{1}$ & $\mathbf{2}$ & $\mathbf{3}$ & NA & $\mathbf{1}$ & $\mathbf{2}$ & $\mathbf{3}$ \\
\hline$N^{\circ}$ de peças & 172 & 45 & 45 & 13 & 414 & 1 & 4 & 5 \\
\% de peças & 62,5 & 16,4 & 16,4 & 4,7 & 97,6 & 0,2 & 0,9 & 1,2 \\
Mínimo (cm) & -- & 0,7 & 5 & 20,9 & -- & 2,6 & 6,4 & 30,3 \\
Máximo $(\mathrm{cm})$ & -- & 4,9 & 17,5 & 111 & -- & 2,6 & 17,13 & 58,2 \\
Média $(\mathrm{cm})$ & -- & 2,9 & 8,2 & 52,1 & -- & 2,6 & 11,9 & 48,2 \\
\hline TOTAL & \multicolumn{3}{c}{275} & & & 424 & \\
\hline
\end{tabular}

NA - Não Apresentou I - Pequeno: Rachaduras de até 5 cm; 2 - Médio: Rachaduras de 5, I a $20 \mathrm{~cm} ; 3$ - Grande: Rachaduras superiores a $20 \mathrm{~cm}$.

Para a classe de menor diâmetro, obteve-se rachaduras de $0,7 \mathrm{~cm}$ a $111 \mathrm{~cm}$ de comprimento, e para a classe superior, de 2,6 a $58,2 \mathrm{~cm}$. Todavia, a classe superior teve mais rachaduras acima de 20 $\mathrm{cm}$ (grandes) do que a classe inferior, que apresentou maior número de rachaduras enquadradas nas categorias pequena e média. Destacando, entretanto, que as rachaduras avaliadas apresentavam pequena largura (trincas superficiais), não chegando a separar a tábua em partes devido à sua presença.

\section{Presença de esmoado nas peças}

A presença de esmoado nas peças resultantes do desdobro é um defeito que causa grande impacto no rendimento de madeira serrada de Cupressus lusitanica e pode ser observada na Tabela 5.

Tabela 5. Presença de esmoado nas peças de madeira serrada de C. lusitanica.

Table 5. Presence of edge grinding in C. lusitanica lumber pieces.

\begin{tabular}{lcc}
\hline \multirow{2}{*}{ Defeitos } & \multicolumn{2}{c}{ Esmoado } \\
\cline { 2 - 3 } & Classe I & Classe II \\
\hline \% peças com defeito & 11,5 & 11,0 \\
Mínimo (cm) & 13,5 & 10,2 \\
Máximo (cm) & 119 & 102 \\
Média (cm/peça) & 6,0 & 5,6 \\
\hline
\end{tabular}

Para a classe I o resultado do rendimento descontando as perdas pela presença de esmoado foi de $55,9 \%$ e para a classe II foi de 55,34\%. Nota-se por meio da Tabela 5 que houve uma equivalência da porcentagem de peças com o defeito, 11,50\% para a Classe I e 11,00 \% para a Classe II. Ao mesmo tempo, observa-se que o efeito do defeito supracitado apresentou maior amplitude na Classe I com valores mínimos e máximos superiores aos observados na Classe II.

\section{CONCLUSÕES}

O maior rendimento bruto do desdobro das toras de Cupressus lusitanica foi obtido no desdobro das toras da classe diamétrica inferior, 20 a $27 \mathrm{~cm}$. Contudo o maior rendimento líquido ocorreu na classe diamétrica superior, acima de $27 \mathrm{~cm}$, demonstrando assim, a maior influência dos defeitos naturais e de processo na classe inferior.

Não foram constatadas tábuas com defeitos de encurvamento e encanoamento. A classe diamétrica superior apresentou maior quantidade de peças arqueadas, porém, com flechas de arqueamento pouco expressivas.

A classe diamétrica inferior apresentou maior quantidade de peças com incidência de nós e os nós se expressaram com maior gravidade que os observados nas tábuas oriundas das toras da classe superior.

Em relação à presença de rachaduras, observou-se que a classe I teve maior número de tábuas com defeito e maior comprimento máximo de rachadura. 
Cunha et al. - Rendimento em madeira serrada de Cupressus

lusitanica Mill por meio do sistema de desdobro tangencial

O Cupressus lusitanica apresentou bom desempenho quando submetido ao processo de desdobro tangencial quando comparado a outras espécies de coníferas, porém faz-se necessário a avaliação após o processo de secagem, onde as peças poderão apresentar comportamento diferenciado.

\section{REFERÊNCIAS BIBLIOGRÁFICAS}

ALMEIDA, C. C. F. Avaliação da qualidade da colagem da madeira de Cupressus lusitanica Mill. para a produção de painéis colados lateralmente (Edge Glued Panel - EGP). 2015. 127 p. dissertação (Mestrado em Engenharia Florestal) - Universidade do Estado de Santa Catarina, Lages, 2014.

ABNT - ASSOCIAÇÃO BRASILEIRA DE NORMAS TÉCNICAS - NBR ISO 1030: Determinação da densidade básica, 2010.

ABNT - ASSOCIAÇÃO BRASILEIRA DE NORMAS TÉCNICAS. NBR ISO 12297:1991: Madeira serrada de coníferas provenientes de reflorestamento, para uso geral - Medição e quantificação de defeitos - Procedimento, out. 1991.

ALVES, I. C. N.; GOMIDE J. L.; COLODETTE, J. L.; SILVA, H. D. Caracterização tecnológica da madeira de Eucalyptus benthamii para produção de celulose Kraft. Ciência Florestal, Santa Maria, v. 21, n. 1, p. 167-174, jan./mar. 2011.

BIASI, C.; ROCHA, M. P. Rendimento em serraria de Pinus elliottii. In: CONGRESSO FLORESTAL BRASILEIRO, 8, 2003, São Paulo. Anais... São Paulo: SBS, 2003.

CADEMARTORI, P. H. G. Qualidade da madeira serrada de Pinus elliottii Engelm procedente de florestas resinadas da região Sul do Rio Grande do Sul. 2010. 82 p. Monografia (Trabalho de Conclusão de Curso, Faculdade de Engenharia Industrial Madeireira) - Universidade Federal de Pelotas, Pelotas, 2010.

CADEMARTORI, P. H. G.; GATTO, D. A.; STANGERLIN, D. M.; SCHNEID, E.; HAMM, L. G. Qualidade da madeira serrada de Pinus elliottii Engelm. procedente de florestas resinadas. Cerne, Lavras, v. 18, n. 4, out./ dez. 2012.

CARDOSO JR., A. A. Inovação tecnológica na obtenção de madeira serrada de pinus com uso de programa otimizador de desdobro. 2008, 140 p. Dissertação (Mestrado em Engenharia Florestal) - Universidade Federal do Paraná, Curitiba, 2008.

EGAS, A. F. Noções sobre a produção de madeira serrada. Maputo: UEM, 2000. 98 p.

FONTES, P. J. P. Auto-suficiência energética em serraria de Pinus e aproveitamento dos resíduos. 1994, 140 p. Dissertação (Mestrado em Engenharia Florestal) - Universidade Federal do Paraná, Curitiba, 1994.

GATTO, D. A.; SANTINI, E. J.; HASELEIN, C. R.; DURLO, M. A.; Qualidade da madeira serrada na região da quarta colônia de imigração Italiana do rio grande do sul. Ciência Florestal, Santa Maria, v. 14, n. 1, p. 223 233, 2004.

IWAKIRI, S.; SILVA, L. S.; TRIANOSKI, R.; BONDUELLE, G. M.; ROCHA, V. Y.; Avaliação do potencial de utilização da madeira de Schizolobium amazonicum "Paricá" e Cecropia hololeuca "Embaúba" para produção de painéis cimento-madeira. Cerne, Lavras, v. 18, n. 2, p. 303-308, 2012a.

IWAKIRI, S.; CUNHA, A. B.; PRATA, J. G.; Braz, R. L.; Castro, V. G.; Kazmierczak, S.; Pinheiro, E.; Rancatti, H.; Sanches, F. L.; Produção de painéis compensados com lâminas de madeira de Sequoia sempervirens e resina ureia-formaldeído. Floresta, Curitiba, v. 42, n. 4, p. 809-816, 2012b. 
IWAKIRI, S.; MATOS, J. L. M.; LIMA, A. J. M.; FERREIRA, E. S.; BATISTA, D. C.; ROMÃO, S. A. A. Produção de painéis compensados de pinus tropicais colados com resina fenol-formaldeído. Floresta, Curitiba, v. 39, n. 3, p. $669-673,2009$.

IWAKIRI, S.; CUNHA, A. B.; TRIANOSKI, R.; BRAZ, R. L.; CASTRO, V. G.; KAZMIERCZAK, S.; PINHEIRO, E.; RANCATTI, H.; SANCHES, F. L. Produção de painéis compensados fenólicos com lâminas de madeira de Sequoia sempervirens. Floresta e Ambiente, Seropédica, v. 20, n. 2, 2013. p. 264-270. KLOCK, U. Qualidade da Madeira de Pinus maximinoi H. E. Moore. 2000. 291 p. Tese (Doutorado em Engenharia Florestal) Universidade Federal do Paraná, Curitiba, 2000.

MANHIÇA, A. A. Rendimento e eficiência no desdobro de Pinus sp. utilizando modelos de corte numa serraria de pequeno porte. 2010, 85 p. Dissertação (Mestrado em Engenharia Florestal) - Universidade Federal do Paraná, Curitiba, 2010.

MURARA JR., M. I.; ROCHA, M. P.; TIMOFEICZYK JR., R. Rendimento em madeira serrada de Pinus taeda para duas metodologias de desdobro. Floresta, Curitiba, v. 35, n. 3, p. 473-483, 2005.

NÉRI, A. C.; FURTADO, F. C.; POLESE, R. C. Desdobro: avaliação do rendimento de madeira serrada de Pinus. Revista da Madeira, Curitiba, n. 88, mai. 2005.

OKINO, E. Y. A.; CAMARGOS, J. A. A; SANTANA, M. A. E.; MARQUES, M. H. B.; MARTINS, V. A.; SOUZA, M. E.; TEIXEIRA, D. E. Descrição dos caracteres tecnológicos da madeira de Cupressus glauca Lam. Scientia Forestalis, Piracicaba, n. 72, p. 39-48, dez. 2006.

OKINO, E. Y. A.; SANTANA, M. A. E.; ALVES, M. V.; MELO, J. E.; CORADIN, V. T. R.; SOUZA, M. R.; TEIXEIRA, D. E.; SOUSA, M. E. Technological Characterization of Cupressus spp. Wood. Floresta e Ambiente, Seropédica, v. 17 , n. 1 , p. $1-11,2010$.

OKINO, E. Y. A.; TEIXEIRA, D. E.; SOUZA, M. R.; SANTANA, M. A. E.; SOUSA M. E. Propriedades de chapas OSB de Eucalyptus grandis e de Cupressus glauca. Scientia Forestalis, Piracicaba, v. 36, n. 78, p. 123-131, jun. 2008.

OLANDOSKI, D. P.; BRAND, M. A.; ROCHA, M. P. Avaliação do rendimento em madeira serrada, qualidade e quantidade de resíduos no desdobro de Pinus spp. Revista do Setor de Ciências Agrárias, Curitiba, v. 17, n. $1-2$, p. $177-184,1998$.

NAUMANN, R. B.; VITAL, B. R.; CARNEIRO, A. C. O.; DELLA LUCIA, R. M.; SILVA, J. C.; CARVALHO, A. M. M. L.; COLLI, A. Propriedades de chapas fabricadas com partículas de madeira de Eucalyptus urophylla S. T. Blake e de Schizolobium amazonicum Herb. Revista Árvore, Viçosa, v. 32, n. 6, p. 1143-1150, 2008.

PEREIRA, J. C. D.; HIGA, R. C. V. Propriedades da madeira Cupressus lusitanica Mill. Colombo: Embrapa Florestas, 2003. 3 p. (Comunicado técnico, 107).

PINTO, I.; KNAPIC, S.; PEREIRA, H.; USENIUS, A. Simulated and realised industrial yields in sawing of maritime pine (Pinus pinaster Ait). Holz als Roh- und Werkstoff, Berlin, v. 64, n. 1, p. 30-36. 2006.

PINTO, J. A. Análise da viabilidade do uso da madeira de "Cryptomeria japonica" para laminação e produção de painéis compensado. Dissertação (Mestrado em Engenharia Florestal) - Universidade Federal do Paraná, Curitiba, 2011, 101 p.

PONCE, R. H. Produção de madeira de qualidade para processamento mecânico. Silvicultura, São Paulo, v. 9, n. 34, p. 9-13, 1984. 
Cunha et al. - Rendimento em madeira serrada de Cupressus

lusitanica Mill por meio do sistema de desdobro tangencial

ROCHA, M. P. Eucalyptus grandis Hill ex Maiden e Eucalyptus dunnii Maiden como fontes dematéria prima para serrarias. 2000, 185 p. Tese (Doutorado em Engenharia Florestal) - Universidade Federal do Paraná, Curitiba, 2000.

ROCHA, M. P. Técnicas e planejamento em serrarias. Curitiba: FUPEF, 2002. 121 p. (Série Didática, 2).

SANTOS, M. P.; AGUILAR, M. T. P. Painéis de madeira como vedação vertical em construções, Cadernos de Arquitetura e Urbanismo, Belo Horizonte, v. 14, n. 15, dez. 2007.

SHIMIZU, J. Y.; RIBAS JR., U. R.; CANCELA, K. C.; MAIOCHI R. A. Cedrinho como alternativa para produção de madeira em pequenas propriedades rurais. Colombo: Embrapa Florestas, 2006. 3 p. (Comunicado Técnico, 172).

TRIANOSKI, R. Avaliação do potencial de espécies florestais alternativas de rápido crescimento para produção de painéis de madeira aglomerada. 2010. 262 p. Dissertação (Mestrado em Ciências Florestais) Universidade Federal do Paraná, Curitiba, 2010.

TSOUMIS, G. Science and technology of Wood: structure, properties, utilization. New York: Champman and Hall, 1991. 494 p.

VIANNA NETO, J. A. Considerações básicas sobre desdobro de Pinus spp. Silvicultura, São Paulo, v. 9, n. 34, p. 15-19, 1984.

VITAL, B.R. Planejamento e Operação de Serrarias. Viçosa: Editora UFV, 2008. 211 p.

Recebido em 30/10/2014

Aceito para publicação em 14/07/2015 